\title{
Inhibition of urokinase-type plasminogen activator receptor induces apoptosis in melanoma cells by activation of p53
}

\author{
R Besch ${ }^{\star, 1}$, C Berking ${ }^{1}$, C Kammerbauer ${ }^{1}$ and K Degitz ${ }^{1}$
}

The urokinase-type plasminogen activator receptor (UPAR) is involved in several biological processes, including proteolysis, adhesion, migration and inflammation. Increased expression of UPAR is associated with metastasis in several tumor types. We studied the biological role of UPAR in melanoma and found that inhibition of UPAR via RNA interference induced massive death in three different metastatic cell lines. Annexin-V staining and caspase activation analysis revealed induction of the mitochondrial apoptotic pathway. The expression of members of the Bcl-2 family (Bax, Bcl-2, Bak and Bcl- $\mathrm{x}_{\mathrm{L}}$ ) was changed in a pro-apoptotic manner. UPAR inhibition induced the expression of the tumor suppressor p53 and of its downstream target gene p21. Inhibition of p53 rescued cells from apoptosis indicating that p53 was critical for apoptosis induction. Apoptosis was observed in melanoma cells carrying activating BRAF mutations and occurred in the presence of extracellular signal-regulated kinase (ERK) phosphorylation. uPAR can activate focal adhesion kinase (FAK), which is implicated in adhesion-dependent tumor cell survival. However, inhibition of FAK did not induce apoptosis. Our data suggest a new function of uPAR acting as a survival factor for melanoma by downregulating p53. Inhibition of UPAR induces a pro-apoptotic signalling pathway via p53 that is independent of ERK or FAK signalling. These findings may offer new treatment strategies for metastatic melanoma.

Cell Death and Differentiation (2007) 14, 818-829. doi:10.1038/sj.cdd.4402065; published online 17 November 2006

Establishment of cancer requires the transformation into a malignant cell phenotype with characteristic features including independence from growth signals, deficiency in apoptosis, sustained angiogenesis, tissue invasion and metastasis. ${ }^{1}$ The urokinase-type plasminogen activator receptor (UPAR) is a molecule that has been implicated in several processes contributing to malignant transformation.

It is part of the proteolytic plasminogen activator system. Many cell types synthesize and secrete the urokinase-type plasminogen activator (UPA), which binds to uPAR. This leads to activation of cell surface bound plasminogen, which in turn cleaves many extracellular matrix components providing pericellular proteolysis. Proteolysis of matrix components supports cell migration, for example, during metastasis. Interference with the plasminogen activator system reduces the invasive and metastatic behavior of various tumors as demonstrated in an extensive array of studies ${ }^{2,3}$ and inhibition of UPAR reduced metastasis in several types of cancer. ${ }^{4-6}$

Besides its role in proteolysis, UPAR is involved in cell adhesion. UPAR associates with several integrins (e.g., $\alpha 3 \beta 1$, $\alpha 5 \beta 1$ or $\alpha \mathrm{M} \beta 2$ ) and modulates their binding behavior to cell surface ligands or to extracellular matrix molecules. ${ }^{7-9}$ Since cell migration is a process that includes tightly regulated steps of adhesion and de-adhesion, the counteracting effects of proteolysis and adhesion mediated by UPAR may play a key role in cell migration and tumor cell invasion and metastasis. ${ }^{10}$
Furthermore, the ability of UPAR to associate with other cell surface proteins can alter intracellular signalling pathways. For example, uPAR is found in focal adhesion sites containing integrins and caveolin that mediate signal transduction via focal adhesion kinase (FAK) or Src kinases. ${ }^{11}$ In cell clones derived from an epidermoid carcinoma cell line uPAR association with $\alpha 5 \beta 1$ integrin activated signalling through FAK and Src kinases. Inhibition of UPAR decreased phosphorylation of FAK, reduced active RAS and ERK and induced dormancy of certain tumor cells. ${ }^{12}$ Upon binding to fibronectin, complexes of UPA, UPAR, $\alpha 5 \beta 1$ and fibronectin activated the EGF receptor independently of secreted growth factors. ${ }^{7}$

Melanoma, due to its tendency towards lymphogenic and hematogenous metastasis, is the most aggressive form of skin cancer. Several studies support an important role of UPAR and the plasminogen activator system in this tumor type. Expression of UPA correlates with the metastatic potential of melanoma cells and the expression of UPA and UPAR is increased in late stage melanocytic tumors. ${ }^{13,14}$ Especially in hypoxic areas of melanoma, high uPAR expression was found. ${ }^{4}$

To study the biological role of UPAR in melanoma, we inhibited expression of UPAR via RNA interference in three metastatic melanoma cell lines. Unexpectedly, inhibition of uPAR induced massive cell death via apoptosis. Cell death

\footnotetext{
${ }^{1}$ Department of Dermatology and Allergology, Ludwig-Maximilian University, Munich, Germany

${ }^{*}$ Corresponding author: Dr R Besch, Department of Dermatology and Allergology, Ludwig-Maximilian University, Frauenlobstr. 9-11, D-80337 Munich, Germany.

Tel: + 49895160 6365; Fax: + 49895160 6202; E-mail: robert.besch@med.uni-muenchen.de

Keywords: melanoma; urokinase receptors; apoptosis; tumor suppressor protein p53; RNA interference

Abbreviations: UPAR, urokinase-type plasminogen activator receptor; uPA, urokinase-type plasminogen activator; ERK, extracellular signal-regulated kinase; FAK, focal adhesion kinase

Received 10.7.06; revised 04.9.06; accepted 13.10.06; Edited by M Blagosklonny; published online 17.11 .06
} 
was accompanied by activation of caspase 3 and caspase 9 suggesting activation of the mitochondrial apoptotic pathway. Expression of members of the Bcl-2 family was changed in a pro-apoptotic manner. UPAR inhibition activated the tumor suppressor p53 and its downstream target gene p21 and inhibition of p53 rescued cells from apoptosis. Apoptosis was induced in cells carrying activating BRAF mutations and occurred without significant reduction of ERK phosphorylation. The observed cell death was not mediated by FAK signalling because inhibition of FAK by RNA interference did not induce apoptosis. We conclude that UPAR expression is essential for survival of melanoma cell lines. Inhibition of uPAR induces a new pro-apoptotic signalling pathway that is activated by $p 53$ and that is independent of FAK signalling and of MAP kinase signalling involving ERK.

\section{Results}

Design and activity of uPAR-targeting siRNAs. The UPAR mRNA was screened for suitable siRNA targets. Several sequences were identified and siRNAs were designed (see Materials and Methods). Their efficacy to inhibit UPAR expression was evaluated by transfection into 1205Lu metastatic melanoma cells and subsequent quantitative RT-PCR. All siRNAs efficiently reduced UPAR mRNA by $84-94 \%$ compared to control siRNAs (Figure 1a). siRNA UP4 was most effective and was used throughout the experiments. A second siRNA, UP3, was also used throughout the experiments to exclude sequence-specific effects of siRNA UP4 other than RNA interference. ${ }^{15}$ On the protein level, siRNA UP3 and UP4 reduced the total a

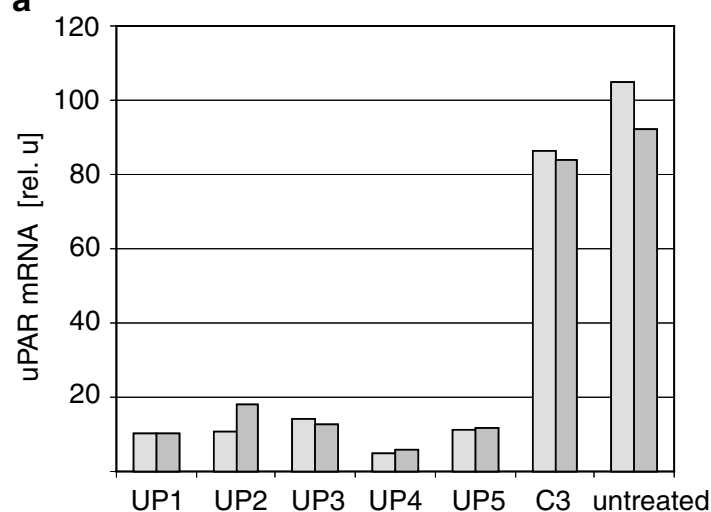

b
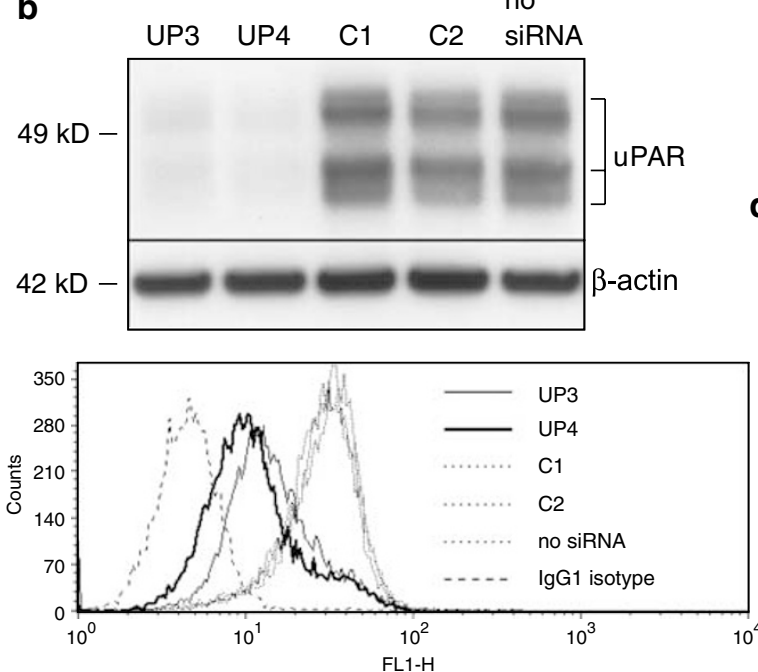
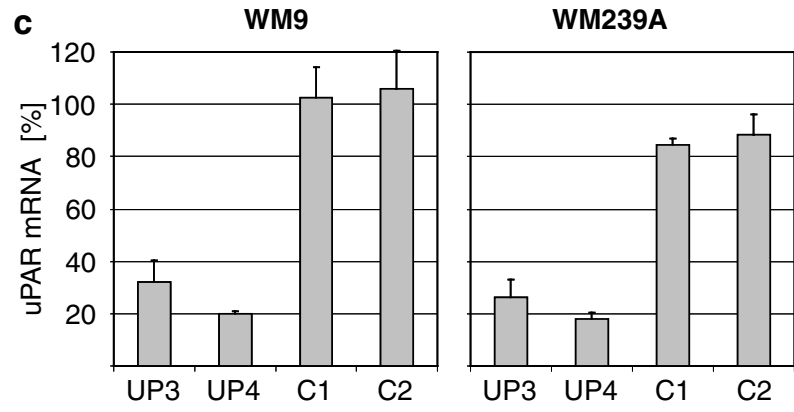

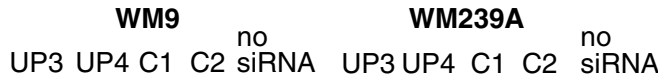
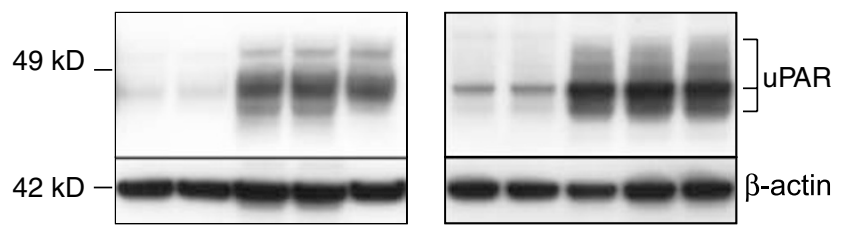

d

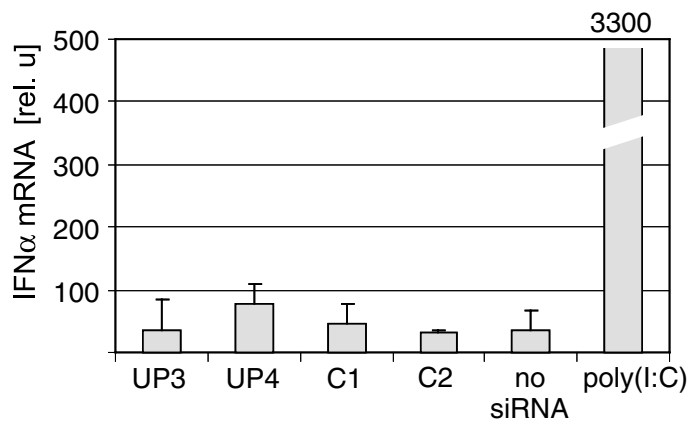

Figure 1 Design and efficacy of uPAR-targeting siRNAs. (a) Efficacy of different uPAR siRNAs was assessed by quantitative RT-PCR. RNA of 1205Lu melanoma cells was prepared $24 \mathrm{~h}$ after siRNA transfection. Two independent transfection experiments are shown and represented with light and dark bars, respectively. (b) Inhibition of uPAR protein. Upper panel: UPAR immunoblots of 1205Lu cells treated with UPAR siRNAs UP3 and UP4, control siRNAs (C1 or C2) or transfection reagent without siRNA (no siRNA) for 3 days. Bands or smears in uPAR immunoblots correspond to different glycolysated forms of UPAR protein. ${ }^{46}$ Detection of $\beta$-actin served as loading control. One representative of three independent experiments is shown. Lower panel: FACS analysis of cell surface UPAR 3 days after transfection. One representative of three independent experiments is shown. (c) Efficacy of uPAR siRNAs in two other metastatic melanoma cell lines (WM9, WM239A). Quantitative RT-PCR for uPAR mRNA was carried out $24 \mathrm{~h}$ after siRNA transfection (upper panel). uPAR expression of cells treated with transfection reagent, but without siRNA, was set to $100 \%$. Mean \pm S.D. of three independent experiments. UPAR immunoblots of cells treated with siRNAs for 3 days (lower panel). Detection of $\beta$-actin served as loading control. One representative of three independent experiments is shown. (d) Immunostimulatory activity of UPAR siRNAs. 1205Lu cells were analyzed by quantitative RT-PCR for induction of IFN $\alpha$ mRNA after treatment with siRNAs for $10 \mathrm{~h}$. Treatment with $400 \mathrm{ng}$ poly $(\mathrm{l}: \mathrm{C})$ for $10 \mathrm{~h}$ served as positive control. Mean \pm S.D. of three independent experiments is shown 
amount of UPAR as detected in Western blots (Figure 1b, upper panel). To test whether UPAR inhibition was also accompanied with a reduction of cell surfacebound UPAR, cells were analyzed by FACS. Extracellular UPAR was significantly decreased by different siRNAs and most prominently with siRNA UP4 (Figure 1b, lower panel). Similar results were obtained in two other metastatic melanoma cell lines on RNA and protein level (Figure 1c). To exclude off-target effects due to immunostimulatory activity, $^{16}$ siRNAs were examined for their potential to activate IFN $\alpha$. When $1205 \mathrm{Lu}$ cells were treated with siRNAs for $10 \mathrm{~h}$, no significant induction of IFN $\alpha$ mRNA was observed, whereas treatment with positive control poly(I:C) led to an approximately 100-fold increase in IFN $\alpha$ mRNA (Figure 1d). Similar results were obtained for other melanoma cell lines WM9 and WM239A (data not shown).

Taken together, the results demonstrate an efficient inhibition of UPAR by RNA interference in melanoma cells with SiRNA UP4 being more effective than UP3. Immunostimulatory activity of siRNA in melanoma cells was not detected.

\section{Inhibition of UPAR reduces the amount of viable cells} and leads to melanoma cell death. After extended exposure to UPAR siRNAs, reduced cell numbers were observed. Time-course experiments with three different metastatic melanoma cell lines revealed a reduction of cell viability between day 3 and day 4 after transfection (Figure 2a). In a further set of experiments, viable cells were quantified at time points at which growth suppression was clearly discernible in the respective cell lines. UPAR siRNAs revealed a significantly reduced amount of viable cells (Figure 2b). The siRNA UP4 was found to be more effective than UP3 leading to a decrease in viable $1205 \mathrm{Lu}$ or WM239A cells to $25-30 \%$ after 5 days. WM9 cells were found to be more sensitive to UPAR inhibition with a reduction to $18 \%$ on day 4 after transfection.

Microscopic evaluation for longer time periods suggested that cell death contributed to the reduction of viable cells. When transfected with siRNA UP4 1205Lu cells displayed a more rounded phenotype on day 3 and only a few cells remained on day 6 (Figure $2 \mathrm{c}$, left panel). siRNA UP3 reduced cell numbers to approximately $50 \%$ on day 6 and almost complete cell death was observed on day 9. Other uPARtargeting siRNAs (UP1, UP2 and UP5) also led to morphologic changes and reduced cell numbers (data not shown). Similar results were obtained with other melanoma cell lines
(Figure 2c, right panel). Consistent with the cell viability assays, WM9 cells were most sensitive to UPAR inhibition with marked reduction of cell numbers already 3 days after transfection.

Cell death was confirmed and quantified by propidium iodide staining (Figure 2d). Depending on the cell line, the number of propidium iodide positive cells was significantly increased (two- to four-fold) in siRNA UP4-treated cells, resulting in $30-80 \%$ propidium iodide positive cells. Again, siRNA UP3 treatment was less effective, resulting in a 1.52-fold increase.

Inhibition of UPAR induces apoptosis in melanoma cells. To delineate the mechanisms responsible for the observed cell death, cells were analyzed for an apoptotic phenotype by Annexin- $V$ staining. A significant increase in apoptotic cells was observed in 1205Lu cells with siRNA UP4 (Figure 3a). 1205Lu (28.7\%) cells were positive for Annexin-V and the number of apoptotic cells was approximately 10fold lower when cells were treated with control siRNAs. Treatment with siRNA UP3 also increased the number of apoptotic cells, however to a less extent than UP4. These experiments were extended also to other melanoma cell lines (Figure 3b). In WM239A cells, the number of apoptotic cells was increased by approximately seven-fold by siRNA UP4, resulting in $25 \%$ apoptotic cells. WM9 cells showed a 2.5 -fold increase in apoptotic cells. The number of apoptotic cells in cell line WM9 was lower (10\%) suggesting a different kinetic of the apoptotic process.

Next, cells were analyzed for caspase activation (Figure 3c). When effector caspase 3 was analyzed, the amount of active caspase 3 subunits was increased in all cell lines treated with siRNA UP4. To characterize the type of apoptosis initiation, caspase 9, representative for the mitochondrial apoptosis pathway, and caspase 8, typically involved in receptor-mediated apoptosis, ${ }^{17}$ were analyzed. The amount of active caspase 9 was clearly increased in all cell lines transfected with siRNA UP4. Analysis of caspase 8 revealed a less consistent activation pattern. In 1205Lu cells, low amounts of procaspase 8 and no active subunits were detected. In WM9 cells, activation of caspase 8 was observed in cells after treatment with siRNA UP4, whereas in WM239A only a small amount of active caspase 8 subunits was detectable.

Taken together, these results suggest that inhibition of uPAR induces apoptosis in melanoma cell lines. Caspase activation suggests that the apoptotic process is initiated predominantly by the mitochondrial pathway.

\footnotetext{
Figure 2 siRNA-mediated inhibition of uPAR reduces the amount of viable melanoma cells and induces cell death. (a) Time course of cells transfected with uPAR siRNAs UP3 and UP4 (black boxes) or control siRNAs C1 and C2 (white boxes). Viable cells were quantified daily. Day of transfection was termed day 0 . Additionally WM9 and WM239A cells were re-transfected on day 5. (b) Quantification of viable melanoma cells treated with uPAR or control siRNAs on day 5 (1205Lu, WM239A) or day 4 (WM9) after transfection. The amount of viable cells treated with transfection reagent, but without siRNA, was set to $100 \%$. Mean \pm S.D. of three independent experiments. ${ }^{*} P=0.05$; ${ }^{\star \star} P=0.01$ compared to any of the control siRNAs. (c) Microscopic pictures of melanoma cells. Left panel: $1205 \mathrm{Lu}$ cells before ( 0 day) and after transfections ( 6 day, 9 day) with siRNA UP3, UP4 or control siRNAs (C1, C2). Right panel: WM9 before ( 0 day) and on day 3 after transfection (upper right panel) and WM239A before ( 0 day) and on day 6 after first transfection (lower right panel). First transfection was on day 0; transfection was repeated on day 6 for 1205Lu and WM239A. Insets show cell morphology at a fourfold higher magnification. One representative among three independent experiments. (d) Cells were transfected with siRNAs and dead cells were assessed by propidium iodide staining and flow cytometry on day 5 (1205Lu and WM239A) or day 4 (WM9). Mean \pm S.D. of three independent experiments. ${ }^{*} P=0.05 ;{ }^{* \star} P=0.01$ compared to any of the control siRNAs
} 
uPAR inhibition changes expression of Bcl-2 family members. Proteins of the Bcl-2 family were analyzed next, because they are typically involved in mitochondrial apoptosis and the ratio between pro- and antiapoptotic members is an important indicator for the commitment to undergo apoptosis or not. ${ }^{18}$ In uPAR-inhibited cells, levels of the pro-apoptotic Bax were elevated, most prominently in 1205Lu cells (Figure 4). In contrast, protein levels of

$$
\text { a }
$$

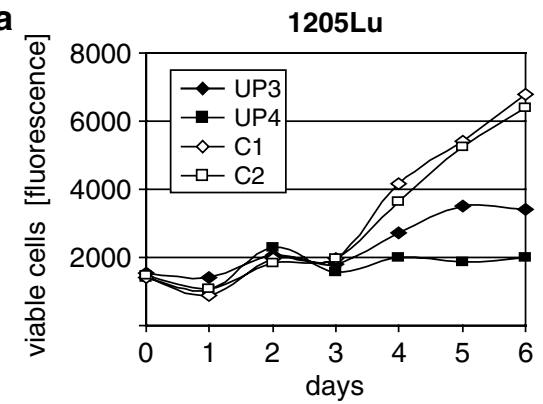

b

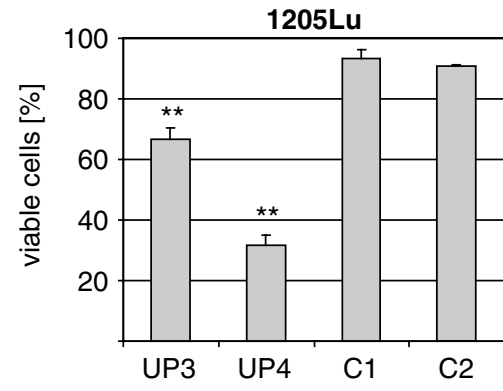

C

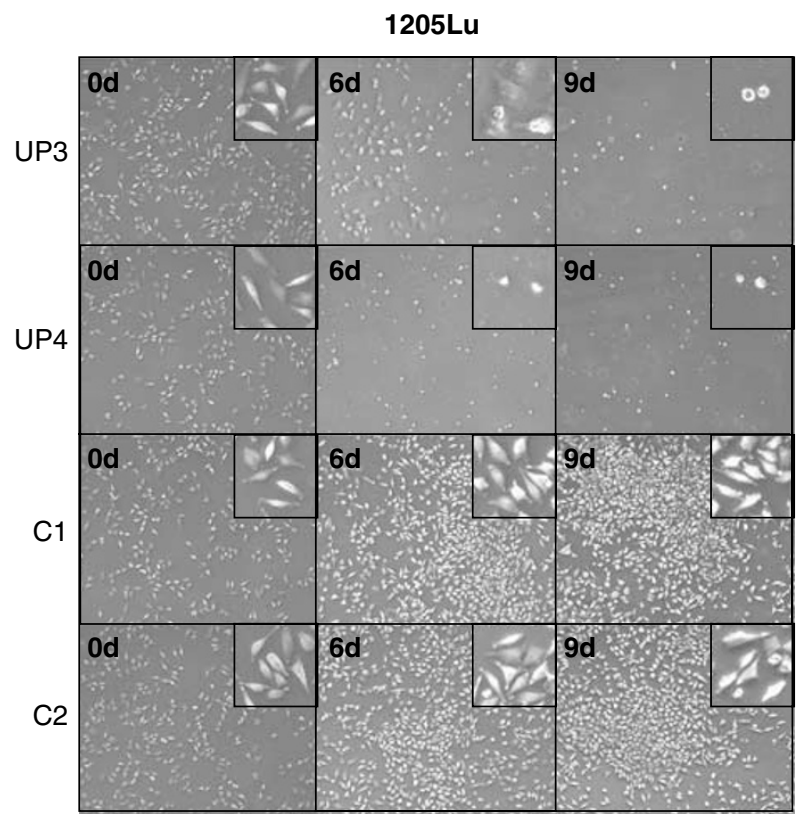

d

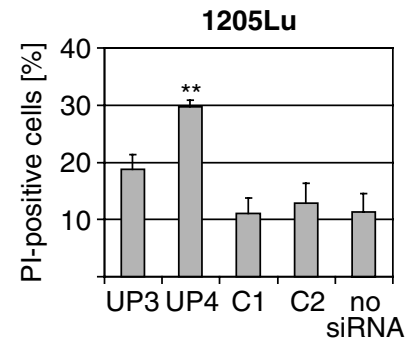

WM9

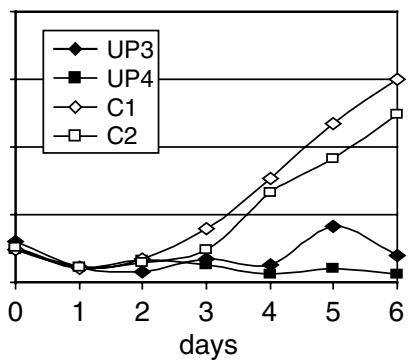

WM9

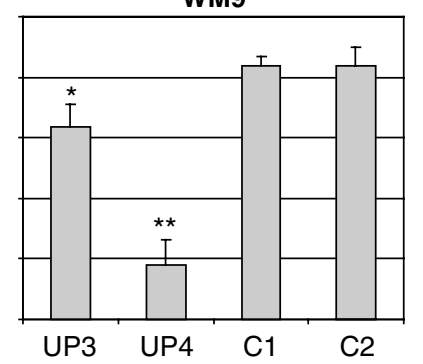

WM239A

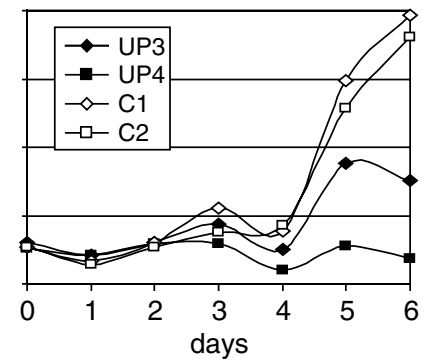

WM239A

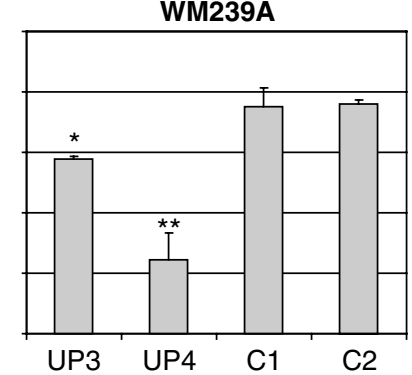

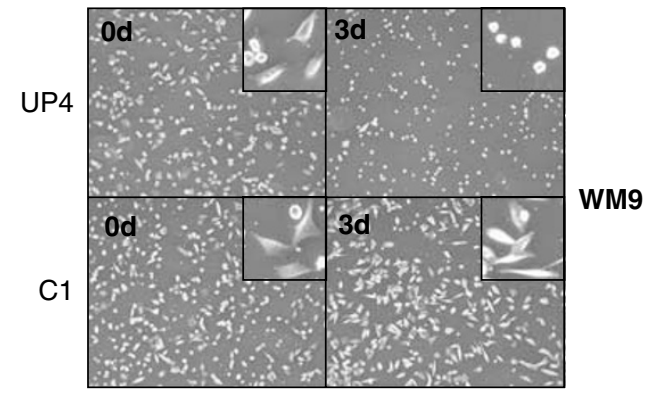
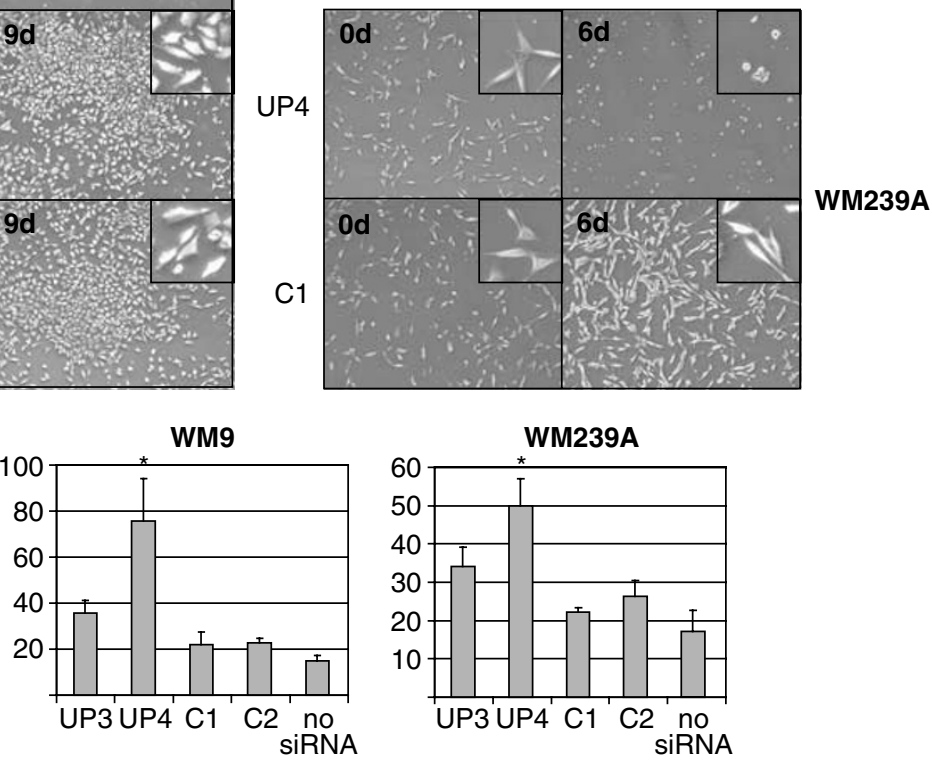
a

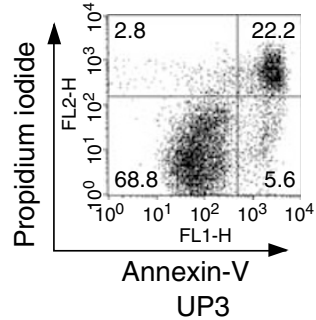

b

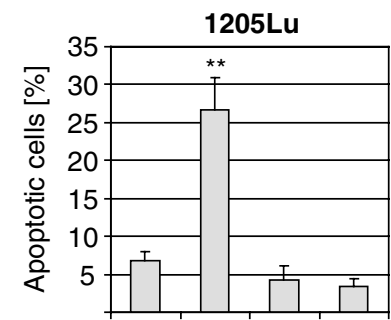

UP3 UP4 C1 C2

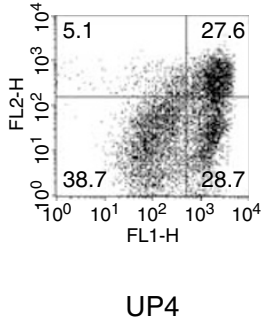

UP4

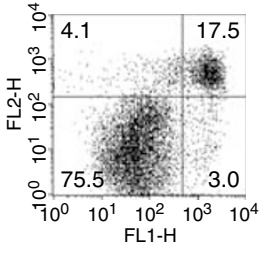

C1

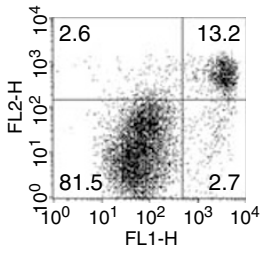

$\mathrm{C} 2$
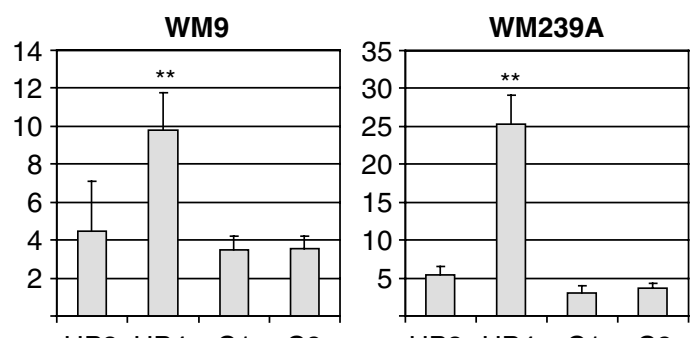

C

WM9

WM239A

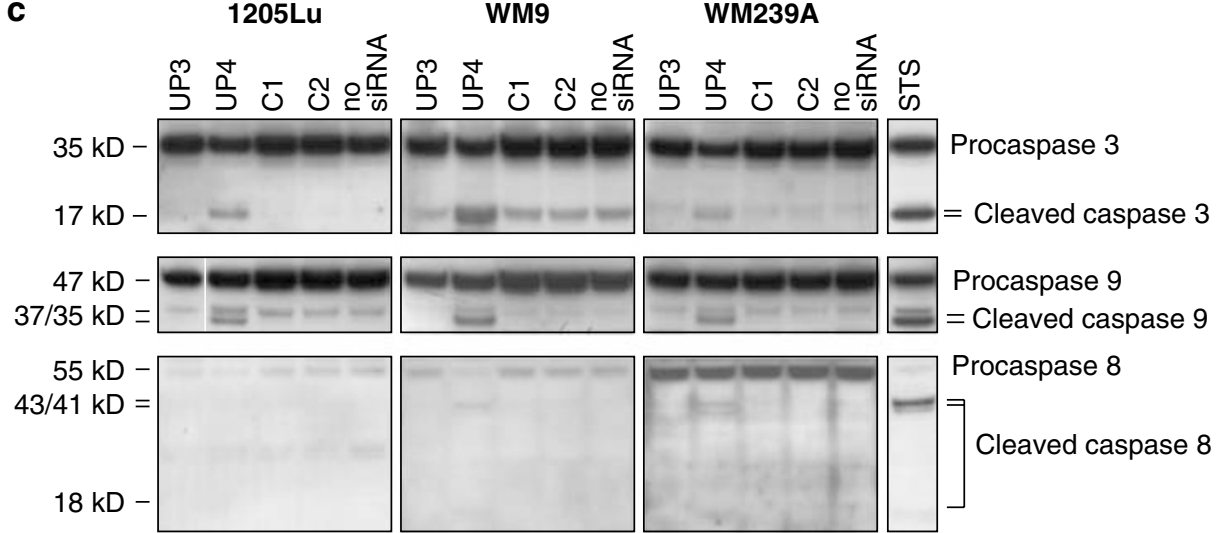

Figure 3 Inhibition of UPAR induces apoptosis. (a) FACS analysis of 1205Lu cells on day 5 after siRNA transfection. Apoptotic cells were determined by Annexin-V staining and counterstaining with propidium iodide. One representative of three independent experiments. (b) Quantification of apoptotic melanoma cells after uPAR inhibition. FACS analysis on day 5 (1205Lu, WM239A) or day 4 (WM9) after transfection. Apoptotic cells were defined as Annexin-V positive but propidium iodide negative cells. Mean \pm S.D. of three independent experiments. ${ }^{*} P=0.05 ;{ }^{*} P=0.01$ compared to any of the control siRNAs. (c) Activation status of effector caspase 3 and initiator caspases 8 and 9 . Cells were analyzed on day 3 after transfection with siRNAs. Activation was assessed with antibodies that are specific both for procaspases and for their respective active cleaved subunits. Molecular weights of procaspases or their respective subunits are indicated. WM9 cells treated with $1 \mu \mathrm{M}$ staurosporine (STS) for $5 \mathrm{~h}$ served as a positive control for caspase cleavage. Blots are representative of three independent experiments

antiapoptotic $\mathrm{Bcl}-2$ were reduced in cells treated with uPAR siRNAs. Additionally, protein levels of pro-apoptotic Bak and antiapoptotic $\mathrm{Bcl}-\mathrm{x}_{\mathrm{L}}$ were analyzed and, consistently, a proapoptotic change in expression of these Bcl-2 family members was observed. The results were similar for all three cell lines (Figure 4).

Apoptosis in uPAR-inhibited cells is mediated by the tumor suppressor p53. In an attempt to identify intracellular pathways relevant for the observed cell death, an array-based screening for cancer-associated mRNAs was carried out. In these experiments, an increased expression of Bax and p21 mRNA was identified. Since both molecules are targets of p53, p53 was analyzed and a strong increase was found in 1205Lu cells when treated with uPAR-targeting siRNAs. Likewise, p21 RNA and protein were strongly elevated after UPAR siRNA treatment (Figure 5a, upper panel). When other melanoma cell lines were analyzed, strong induction of p53 and p21 was observed to a similar degree (Figure $5 \mathrm{a}$, lower panel).

If apoptosis is mediated by p53, inhibition of p53 should rescue UPAR-inhibited cells from apoptosis. Therefore, a p53-targeting siRNA was designed and transfected alone or together with siRNA UP4 (Figure $5 \mathrm{~b}$ ). At $24 \mathrm{~h}$ after transfection, the efficacy of cotransfected siRNAs was evaluated by RT-PCR. Each siRNA inhibited its corresponding gene efficiently and cotransfection with siRNA UP4 and siRNA p53 reduced mRNA levels of both p53 and uPAR (Figure 5b, upper panel). When the respective proteins were analyzed 3 days after siRNA transfection, uPAR protein was reduced in cells treated either with siRNA UP4 alone as well as together with siRNA p53, confirming the results on RNA level (Figure 5b, lower right panel). When p53 protein was analyzed, siRNA p53 reduced basal as well as uPAR-induced p53 levels (Figure 5b, lower left panel). Five days after transfection, 1205Lu cells were examined for apoptosis (Figure 5c). Whereas UP4 alone induced apoptosis, cotrans- 

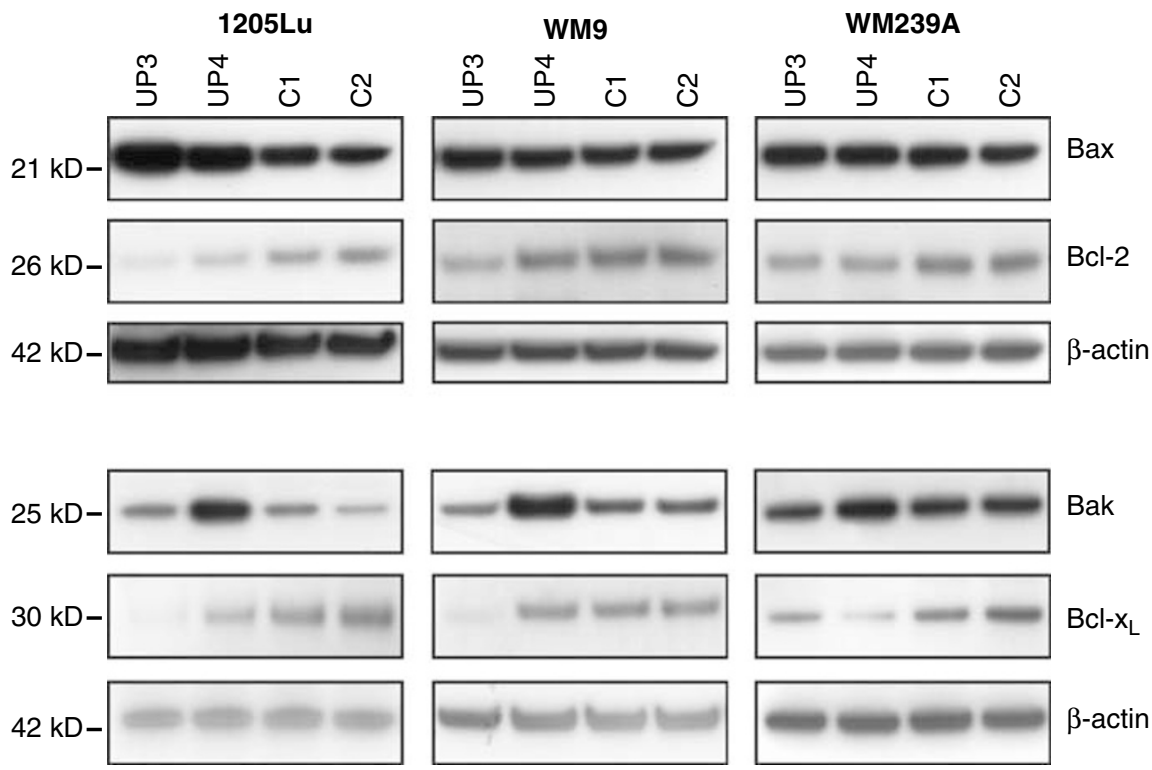

Figure 4 Inhibition of uPAR changes expression of Bcl-2 family members in a pro-apoptotic fashion. Immunoblots of Bcl-2 family members. Pro-apoptotic Bax and Bak and antiapoptotic $\mathrm{Bcl}-2$ and $\mathrm{Bcl}-\mathrm{x}_{\mathrm{L}}$ proteins were analyzed on day 3 after transfection. $\beta$-Actin served as loading control. Blots are representative of three independent experiments

fection with siRNA p53 reduced the amount of apoptotic cells to almost basal levels. To further evaluate the role of p53 in regulation of p21, expression of p21 was analyzed in 1205Lu cells treated with p53- and uPAR-targeting siRNAs. Treatment with siRNA p53 reduced basal, as well as siRNA UP4induced levels of p21 mRNA and protein (Figure $5 \mathrm{~d}$ ).

Taken together, these data suggest that UPAR inhibition activates p53 leading to increased expression of p53 targets, for example, p21. Blocking expression of p53 reduced UPAR siRNA-mediated p53 induction, decreased induction of p21 and rescued cells from apoptosis. This suggests that UPAR promotes melanoma cell survival by downregulation of p53.

Signalling of ERK and FAK is not involved in apoptosis of uPAR-inhibited melanoma cells. Previously, high uPAR expression was shown to support cell proliferation via activation of MAP kinase signalling in an epidermoid carcinoma cell line. ${ }^{7}$ High expression of uPAR leads to phosphorylation of ERK mediated by FAK. ${ }^{12}$ Activation of ERK plays an important role in cell proliferation and survival and high activity of ERK was found to be critical for survival of melanoma cells. ${ }^{19} \mathrm{We}$, therefore, assessed the activation status of ERK in UPARinhibited cells. Surprisingly, immunoblots of UPAR siRNAtreated cells showed only slightly reduced amounts of phosphorylated ERK suggesting that UPAR-induced apoptosis is not critically mediated by ERK signalling (Figure 6a).

Besides its effect on ERK activation, FAK is an important transducer of adhesion-dependent cell survival signalling. High FAK activity is observed in many malignancies including melanoma ${ }^{20}$ and inhibition of FAK can support apoptosis of tumor cells. ${ }^{21}$ FAK can directly interact with p53 and is able to prevent cells from p53-mediated apoptosis. ${ }^{22}$

Since inhibition of UPAR can reduce FAK activity, ${ }^{12}$ we reasoned that apoptosis of melanoma cells may be caused by reduced FAK signalling that leads to activation of $p 53$. When
FAK activation was analyzed by immunoblotting in UPARinhibited cells, a slight to marked reduction of phosphorylated FAK was observed (Figure 6b). Interestingly, total FAK protein was decreased as well, indicating that a transcriptional downregulation of FAK may be involved in uPAR-inhibited cells. Activation of p53 in uPAR-inhibited cells may contribute to that effect because p53 can suppress FAK expression by binding to the FAK promoter. $^{23}$

To test whether FAK signalling is indeed relevant for apoptosis in melanoma cell lines, we inhibited FAK by RNA interference. Two FAK-targeting siRNAs were designed and Western blotting revealed strong suppression of total and phosphorylated FAK to lower levels than observed in UPARinhibited cells (Figure 6c). Melanoma cells were transfected with FAK or control siRNAs and analyzed for apoptosis (Figure 6d). In contrast to uPAR siRNA treatment, cell viability was not affected by inhibition of FAK, whereas treatment with siRNA UP4 resulted in a decrease in viable cells to $20-40 \%$ (Figure 6d, upper panel). Furthermore, in contrast to siRNA UP4-treated cells, the number of apoptotic cells was not increased by FAK siRNAs in 1205Lu and WM239A cells (Figure $6 \mathrm{~d}$, lower panel). These results were confirmed by analysis of caspase 3 activation (data not shown). In contrast, in WM9 the number of apoptotic cells was increased by FAK inhibition, suggesting that FAK is partially involved in apoptosis of these cells. Because the number of viable WM9 cells was not significantly decreased, this effect seems to play a minor role in cell death of WM9.

Taken together, these data suggest that apoptosis induced by UPAR inhibition occurs in the presence of active ERK suggesting an ERK-independent survival pathway in melanoma. Furthermore, FAK-associated survival pathways play a minor role in apoptosis since FAK activity was only slightly decreased by UPAR inhibition and inhibition of FAK by RNA interference did not induce apoptosis. 
a

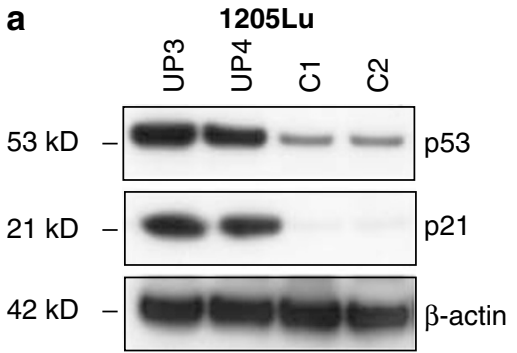

WM9

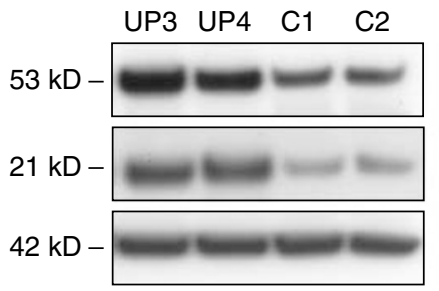

b

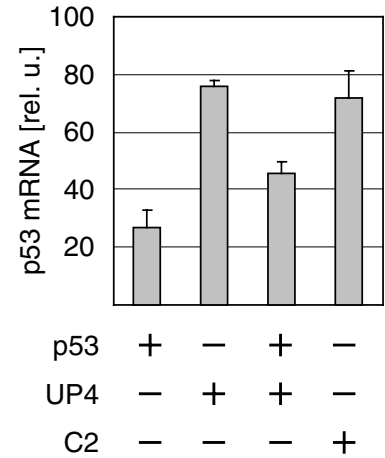

p53

$\beta$-actin

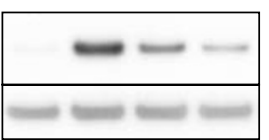

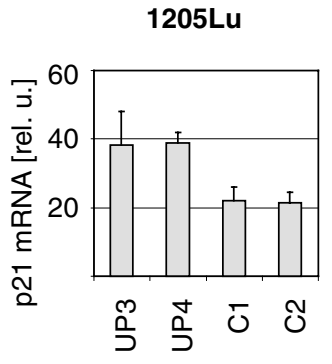

c

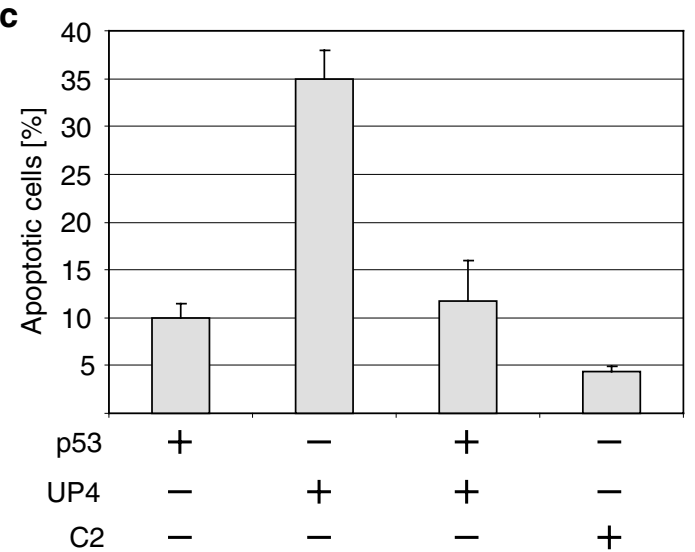

WM239A

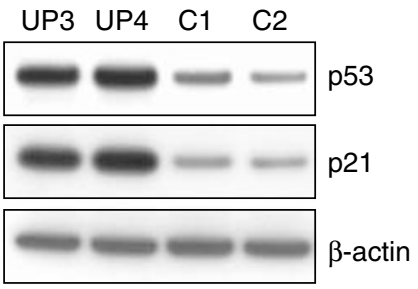

d
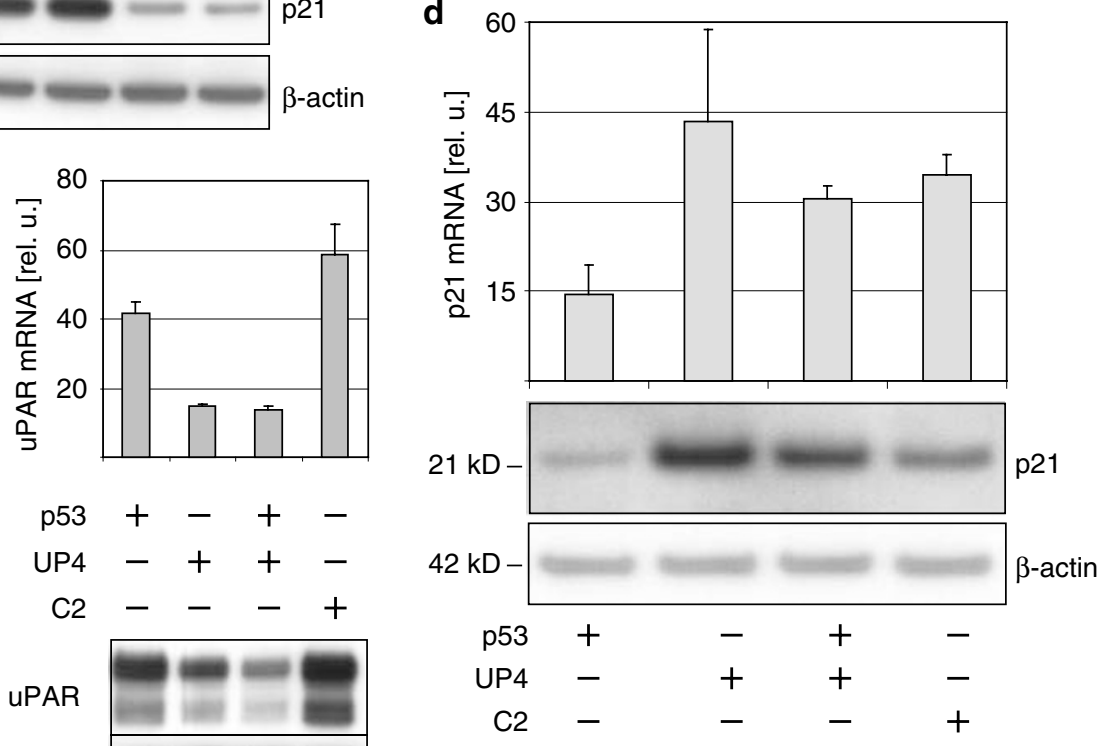

Figure 5 Apoptosis induced by uPAR inhibition is mediated by p53. (a) Inhibition of uPAR induces p53 and its downstream target p21. Upper panel left: Immunoblots for p53 and p21 in uPAR-inihibited 1205Lu cells. Proteins were analyzed on day 3 after transfection with uPAR siRNAs or controls. Upper panel right: Analysis of p21 mRNA 3 days after transfection by quantitative RT-PCR. Lower panel: Immunoblots for p53 and p21 in other uPAR-inihibited melanoma cells, that is, WM9 and WM239A. Proteins were analyzed on day 3 after transfection. The mean \pm S.D. of three independent experiments is shown for RT-PCR experiments. Blots are representative of three independent experiments with $\beta$-actin serving as loading control. (b and $\mathbf{c}$ ) Inhibition of p53 rescues melanoma cells from apoptosis induced by uPAR inhibition. 1205Lu cells were transfected with p53 siRNA, uPAR siRNA UP4, both siRNAs or with control siRNA C2. (b) Analysis of p53 and uPAR inhibition by quantitative RT-PCR $24 \mathrm{~h}$ after siRNA treatment (mean + S.D. of three independent experiments) and by immunoblots for p53 and uPAR on day 3 after transfection. Blots are representative of three independent experiments. (c) Quantification of apoptotic cells by FACS on day 5 after transfection. Apoptotic cells were defined as Annexin-V positive but propidium iodide negative cells. Mean \pm S.D. of three independent experiments. (d) Analysis of the p53 target gene p21 by quantitative RT-PCR and immunoblotting. RNA analysis was carried out 3 days after transfection (mean \pm S.D. of three independent experiments) and immunoblots 4 days after transfection. Blots are representative of three independent experiments

Inhibition of UPAR reduces tumor growth in human melanoma skin reconstructs. To assess the influence of uPAR inhibition in a more natural context, human skin reconstructs were utilized. This model provides the analysis of growth and invasion of melanoma cells in a context similar to human skin. Skin reconstructs consist of a collagen matrix containing primary fibroblasts, representing the dermis, and a multilayer of keratinocytes on the collagen matrix, representing the epidermis. ${ }^{24}$

When 1205Lu cells treated with siRNA UP4 were included in the skin reconstruct, tumor growth was significantly reduced compared to cells treated with control siRNA. Representative histological sections are shown in Figure 7. Four independent skin reconstructs for each siRNA were analyzed and the average volume of tumor nests was found to be approximately three-fold smaller. Furthermore, tumor spread and tumor thickness were found to be decreased by approximately $50 \%$.

This indicates that inhibition of UPAR reduces tumor growth of melanoma cells in a three-dimensional (3D) environment that resembles human skin in vivo.

\section{Discussion}

Here, we report that UPAR, a receptor that is associated with proteolysis and cell migration, acts as a survival factor in melanoma. Effective inhibition of UPAR by RNA interference 
a

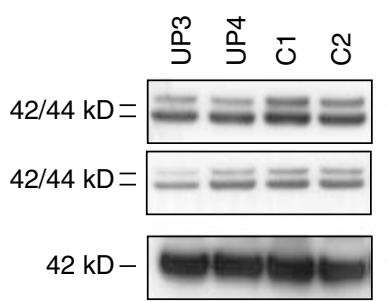

b

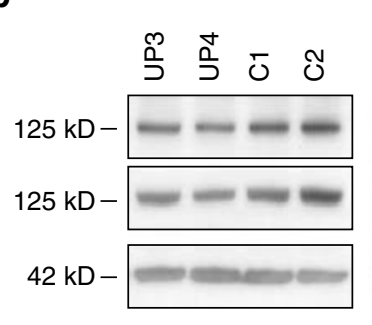

c

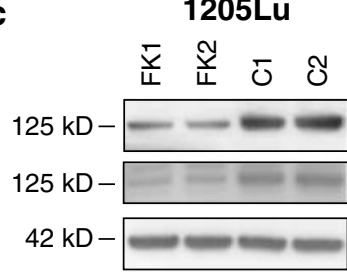

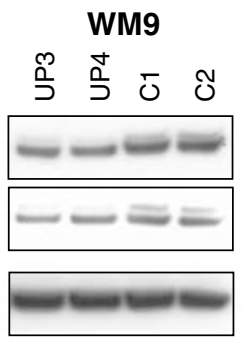

WM9
WM239A

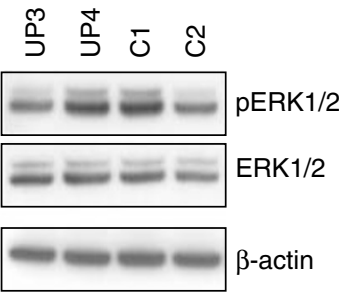

WM239A
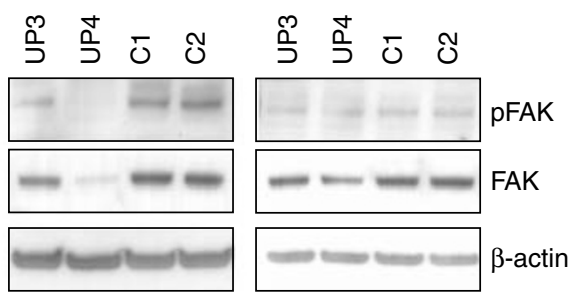

WM239A

WM9
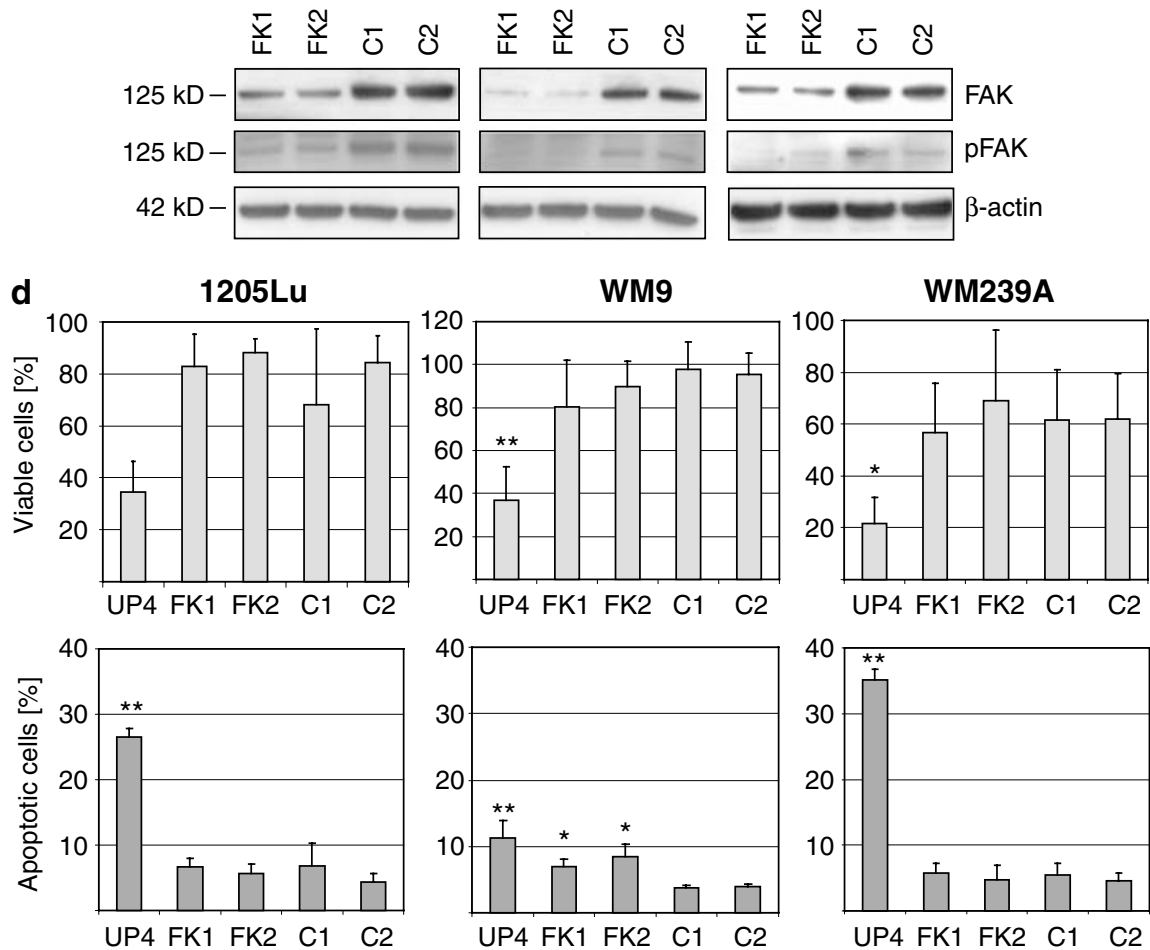

Figure 6 Signalling of ERK and FAK is not involved in apoptosis of uPAR-inhibited melanoma cells. (a) Activation status of ERK in uPAR-inhibited melanoma cells. Immunoblots on day 3 after transfection for active (phosphorylated Y204) and for total ERK1/2. $\beta$-Actin served as loading control. Blots are representative of three independent experiments. (b) Activation status of FAK in uPAR-inhibited melanoma cells. Immunoblots on day 3 after transfection for total FAK and for its active, Y397-phosphorylated form (pFAK). $\beta$-Actin served as loading control. Blots are representative of three independent experiments. (c) Efficacy of FAK-targeting siRNAs. Cells were treated with FAK siRNAs and were analyzed on day 3 after transfection by immunoblotting for total FAK and phosphorylated FAK (pFAK). $\beta$-Actin served as loading control. Representative of three independent experiments. (d) Quantification of viable and apoptotic melanoma cells treated with FAK siRNAs or control siRNAs. Cells treated with siRNA UP4 served as positive control. Cells were analyzed on day 5 (1205Lu, WM239A) or day 3 (WM9) after transfection. Upper panel: Determination of viable cells. The amount of viable cells treated with transfection reagent, but without siRNA, was set to 100\%. Lower panel: Determination of apoptotic cells. Apoptotic cells were defined as Annexin-V positive but propidium iodide negative cells. Mean \pm S.D. of three independent experiments. ${ }^{*} P=0.05 ;{ }^{* *} P=0.01$ compared to any of the control siRNAs

induced apoptosis leading to near complete cell death after 4-14 days depending on the inhibitory strength of the different siRNAs. To our knowledge, such a critical role of uPAR for tumor cell survival has not been described previously. Cell death by UPAR inhibition was observed with two different siRNA sequences in three different metastatic melanoma cell lines. In addition, potential off-targets effects of the siRNAs were addressed by (i) testing the immunostimulatory activity 
UP4

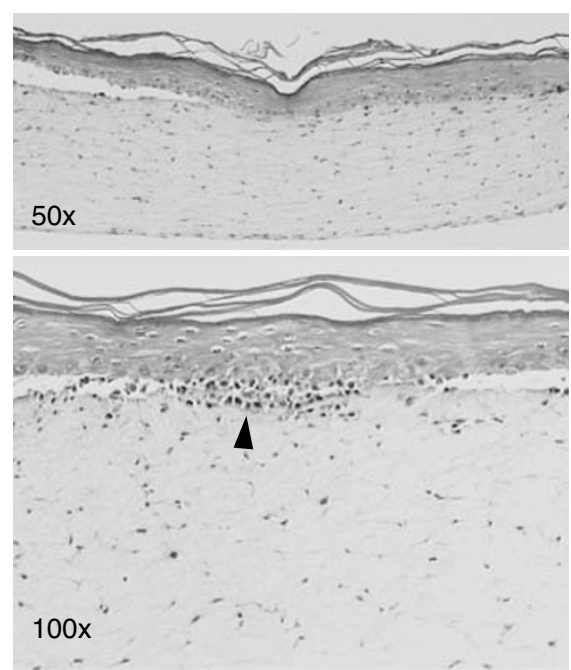

C2

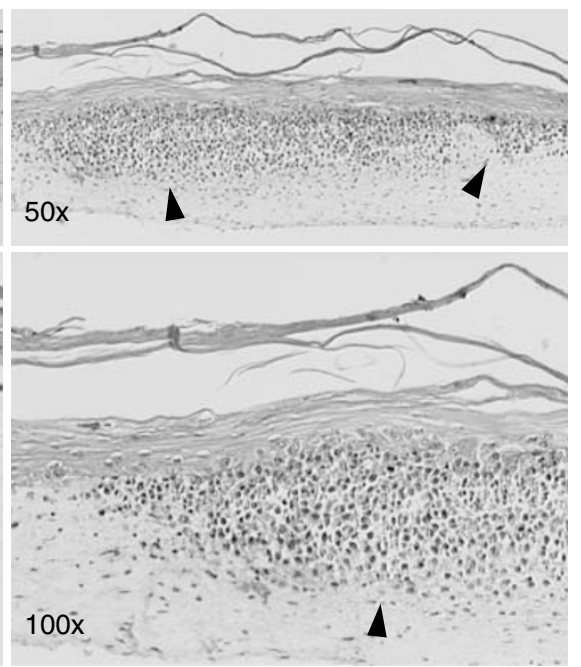

Figure 7 uPAR inhibition reduces tumor growth in human melanoma skin reconstructs. Histological sections of 15 days old melanoma skin reconstructs with normal human fibroblasts, keratinocytes and siRNA-treated melanoma cells. 1205Lu melanoma cells were treated with siRNA UP4 (left panel) or control siRNA C1 (right panel). Tumor nests are indicated with black arrowheads. Representative sections of four independent skin reconstructs are displayed $(\times 50$ upper panel, $\times 100$ lower panel)

represented by induction of IFN $\alpha$ (Figure 1d) and (ii) by lowering the siRNA concentration: $A$ four-fold reduced siRNA concentration resulted in a similar efficiancy of UPAR inhibition, p53 induction and apoptosis thereby minimizing the probability of off-target effects, which would rather apear at high siRNA concentrations (data not shown).

Our data suggest that uPAR inhibition induced cell death via apoptosis. Reduction of invasive and metastatic as well as mitogenic properties due to UPAR inhibition has been documented in various tumors, ${ }^{25}$ but induction of apoptosis by UPAR inhibition has only been described in two other cell types: (i) in a glioma cell line, inhibition of UPAR induced apoptosis $^{26}$ and led to tumor regression in mice. ${ }^{5}$ Since melanocytic cells derive from the same precursors in the neural crest as neuronal cell types, the survival function of uPAR might be similar in both cell types. (ii) Recently, induction of apoptosis was observed in a prostate cancer cell line by inhibition of both UPAR and uPA. ${ }^{27}$ Several of our findings argue for a different mechanism in melanoma: (i) inhibition of UPAR alone, without inhibition of UPA, was sufficient to induce apoptosis; (ii) inhibition of binding of uPA to uPAR with small molecule inhibitors did not result in cell death (data not shown); and (iii) ERK activation was only slightly reduced in some UPAR-inhibited melanoma cells (Figure 6a), but strongly reduced in the prostate cell line.

The tumor suppressor p53 plays a central role in cellular responses to stress stimuli by triggering cell cycle arrest or apoptosis. In human cancer p53 is often mutated leading to apoptosis deficiency and to genetic instability of tumor cells. ${ }^{28}$ Surprisingly, in melanoma, p53 is rarely mutated despite the marked resistance of melanoma cells to irradiation or other stress stimuli. Studies suggest impaired functionality of p53 in melanoma because overexpression of p53 did not induce apoptosis and irradiation led to p53 accumulation but not to apoptosis. ${ }^{29}$ On the other hand, inactivation of p53 contributes to the development of melanocytic tumors in mice ${ }^{30}$ and a recent study demonstrated p53-mediated apoptosis of melanoma cells in a 3D context. ${ }^{31}$ Our study suggests intact functionality of p53 in melanoma: (i) p53 accumulates in uPAR-inhibited melanoma cells and apoptosis is initiated via the mitochondrial pathway that is typical for p53-mediated apoptosis; $^{32}$ (ii) the induction of p53 correlated with an increased expression of its target gene p21; and (iii) inhibition of p53 rescued cells from apoptosis mediated by uPAR inhibition.

Overexpression of $\mathrm{Bcl}-2$ can prevent p53-dependent apoptosis, leading to cellular senescence ${ }^{33}$ and high intrinsic expression of $\mathrm{Bcl}-2$ has been observed in melanocytic cells. ${ }^{34}$ We found that expression of Bcl-2, as well as antiapoptotic $\mathrm{Bcl}-\mathrm{x}_{\mathrm{L}}$, was not increased, but reduced by UPAR inhibition, again pointing towards an antiapoptotic effect of UPAR.

In a recent study, p53-mediated apoptosis was observed in cells with low $\alpha \mathrm{v} \beta 3$ integrin expression when cultivated in collagen gels. ${ }^{31}$ Since uPAR can activate several integrins including $\alpha \mathrm{v},{ }^{35}$ inhibition of UPAR may reduce activation of integrin $\alpha v$ thereby contributing to apoptosis. Despite the observation of apoptosis in melanoma cells in this and our study, several differences exist: (i) in the study by Bao et al., activation of $\mathrm{p} 53$ was induced by post-translational modification with constant amounts of p53 protein, whereas we observed increased amounts of p53; (ii) the expression pattern of p53 targets and apoptosis-related proteins was different, for example, the expression of Bax and Bcl-2 was not altered in that study; (iii) apoptosis was dependent on reduced ERK activity, whereas we observed apoptosis in the presence of active ERK; and (iiii) apoptosis was only induced when cells were cultivated in a collagen gel, whereas we observed apoptosis under conventional cultivation conditions. Nevertheless, reduced $\alpha \mathrm{v}$ integrin activation in uPAR-inhibited melanoma cells may have contributed to apoptosis in skin reconstructs, for example, by post-translational p53 modification. 
Activated ERK can rescue cells from apoptosis and inhibition of ERK signalling can induce apoptosis in melanoma. ${ }^{19}$ Inhibition of UPAR is known to reduce ERK activity. ${ }^{7,12}$ Surprisingly, ERK phosphorylation was only slightly reduced in uPAR-inhibited cells (Figure 6a), yet, these cells underwent apoptosis. This could be due to other activation mechanisms in melanoma, for example, autocrine growth factor stimulation or BRAF mutations. ${ }^{36,37}$ Sequencing analysis revealed that 1205Lu and WM9 carried the more common V600E, whereas WM239A carried a V600D mutation (data not shown), both activating mutations. ${ }^{37}$ At any rate, our results do not support that ERK is important for apoptosis in uPAR-inhibited melanoma cells and suggest that an ERK-independent survival pathway is activated by uPAR.

FAK is an important mediator of adhesion-dependent survival. ${ }^{38}$ In several tumor types, high activity of FAK can promote survival and may contribute to anchorage-independent growth. ${ }^{21,39}$ Our data showed that FAK was reduced in some uPAR-inhibited melanoma cells (Figure 6b). However, reduction of FAK to lower levels than observed in UPARinhibited cells did not induce apoptosis (Figure $6 \mathrm{c}$ and $\mathrm{d}$ ). These results suggest that FAK is not important for survival of melanoma cells. Since high activity of ERK can rescue cancer cells from apoptosis induced by FAK inhibition, ${ }^{39}$ it may be speculated that constitutive BRAF activation compensates reduced $F A K$ signalling in melanoma.

We aimed at testing the effect of UPAR inhibition in an in vivo model to evaluate tumor growth and invasion of UPARinhibited cells. The application of siRNAs in animal models suffers from low stability and high elimination rates. We, therefore, utilized human skin reconstructs. This model resembles the natural skin environment, that is, cell-cell or cell-matrix cross-talk and allows to analyze growth and invasion of uPAR-inhibited melanoma cells. siRNA-mediated inhibition of UPAR was very effective, because a single treatment with siRNA resulted in reduction of tumor growth and invasion after 15 days. Additional apoptosis-promoting mechanisms may have contributed to the observed effect, for example, due to the cultivation of cells under 3D conditions in the skin reconstruct. ${ }^{31}$ We also analyzed the skin reconstructs for apoptosis and cell proliferation by immunhistochemistry and found no difference between siRNA UP4-treated and control melanoma cells (data not shown). This may be due to the late time point of analysis, which was 15 days after start of 3D cultivation as opposed to 5 days when onset of apoptosis was observed in $2 \mathrm{D}$ cultivation.

In conclusion, we found that UPAR is an essential survival factor for melanoma cells. UPAR inhibition results in massive cell death via apoptosis. Apoptosis was mediated by p53 and occurred in the presence of active ERK signalling in melanoma cells that carry activating BRAF mutations. This pathway is independent of FAK signalling, because inhibition of FAK did not induce apoptosis in melanoma cells. These results are of particular importance because active ERK can rescue tumor cells from various apoptotic stimuli and is constitutively activated in melanoma. Therefore, the identification of new ERK-independent cell death-promoting pathways is of interest for the understanding of melanoma biology and may open new strategies for the treatment of melanoma.

\section{Materials and Methods}

Reagents and antibodies. Anti-uPAR (IITD) antibody was a kind gift of V Magdolen (Technical University of Munich, Germany) or was from R\&D Systems (Wiesbaden-Nordenstadt, Germany). Anti-Bax (2D2), anti-ERK1/2, antiphosphoERK1/2 (E-4), anti-p21 (F-5) antibodies and HRP-conjugated goat anti-rabbit IgG were purchased from Santa Cruz Biotechnology (Heidelberg, Germany). Anticaspase 3, anti-caspase 8 (1C12), anti-caspase 9, anti-FAK, anti-Bak, anti-Bcl- $\mathrm{x}_{\mathrm{L}}$ and HRP-conjugated horse anti-mouse IgG were obtained from New England Biolabs (Frankfurt, Germany). Anti-Bcl-2 (Ab-1) and anti-p53 (Ab-6) antibodies were from Merck Biosciences (Schwalbach/Ts., Germany), anti- $\beta$-actin (AC-15) antibody was from Sigma (Taufkirchen, Germany) and antiphospho-Y397 FAK antibody was from Biosource (Solingen, Germany). Small interfering RNAs (siRNAs) were purchased from Thermo Electron (UIm, Germany) or MWG Biotech (Ebersberg, Germany). PCR primers were obtained from MWG Biotech.

siRNA Design. siRNAs targeting uPAR (RefSeq number NM_002659) FAK (RefSeq number NM_005607) or p53 (RefSeq number NM_000546) were designed according to the published guidelines. ${ }^{40,41} 3^{\prime}$ overhangs were carried out as dTdT. Sequences of non-silencing control siRNAs were designed to contain random sequences that do not match within the human genome. According to recommendations, ${ }^{15}$ two siRNAs and two control siRNAs were used for most experiments. The sequences of the $19 \mathrm{nt}$ sense strand of each siRNA are: UP1: CGGACUGGCUUGAAGAUCA; UP2: GCCGUUACCUCGAAUGCAU; UP3: CAUUUCCUGUGGCUCAUCA; UP4: GAUCCAGGAAGGUGAAGAA; UP5: CCAA UGGUUUCCACAACAA; FK1: ACACCAAAUUCGAGUACUA; FK2: GAAGUCUAA CUAUGAAGUA; C1: GCGCAUUCCAGCUUACGUA; C2: GCGCUAUCCAGCUU ACGUA; C3: UUCUCCGAACGUGUCACGU and p53; CUACUUCCUGAAAA CAACG.

Cell culture. Human melanoma cell lines were a kind gift of M Herlyn (Wistar Institute, Philadelphia, PA, USA). All were metastatic and isolated from clinically and histologically defined lesions. WM239A and WM9 cells are derived from lymph nodes and 1205Lu was isolated from a lung metastasis. They were maintained in a culture medium consisting of MCDB153 (Sigma) with 20\% Leibovitz's L-15 (PAA Laboratories, Coelbe, Germany), 2\% FBS (PAA Laboratories), $1.68 \mathrm{mM} \mathrm{CaCl}$ (Sigma) and $5 \mu \mathrm{g} / \mathrm{ml}$ insulin (Sigma). For analysis, cells were detached as described $^{42}$ with $0.2 \%$ EDTA in PBS in order to maintain intact uPAR on the cell surface. Keratinocytes and fibroblasts used in skin reconstructs were isolated from neonatal human foreskins and cultivated as described. ${ }^{43}$

Transfection with siRNAs. siRNA (240 pmol) diluted with Opti-MEM (Invitrogen, Karlsruhe, Germany) to a final volume of 100 and $6 \mu \mathrm{l}$ Oligofectamine (Invitrogen) in $30 \mu \mathrm{l}$ Opti-MEM were mixed and incubated for $30 \mathrm{~min}$ at room temperature for complex formation. Transfection mixture was added together with culture medium to cells in $3.5 \mathrm{~cm}$ dishes to give a final volume of $1 \mathrm{ml}$. Transfection with FITC-labelled siRNA revealed approximately $90 \%$ of cells with increased fluorescence when analyzed by FACS after $24 \mathrm{~h}$. Preliminary experiments showed that medium replacement strongly decreases cellular fluorescence as well as inhibitory activity of siRNA. Therefore, an individual transfection scheme was established that was appropriate for each cell line in longer lasting experiments. Unless indicated otherwise, 1205Lu and WM239A cells were re-transfected on day 3 after first transfection by adding new transfection mixture in $1 \mathrm{ml}$ culture medium, whereas WM9 cells were transfected only once. Cotransfection studies in Figure $5 \mathrm{~b}$ were carried out with $120 \mathrm{pmol}$ of the respective inhibiting siRNAs (siRNA p53 and UP4) or 240 pmol of control siRNA (C2).

RNA extraction and quantification. Total RNA was extracted from cells using Trizol (Invitrogen) as described by the manufacturer and analyzed by quantitative RT-PCR. RNA $(1 \mu \mathrm{g})$ was reverse transcribed using Expand Reverse Transcriptase (Roche Diagnostics, Mannheim, Germany) and poly(dT) oligonucleotide (Roche) according to the manufacturer's protocol. Quantitative PCR was performed using the FastStart DNA Master SYBR Green I Kit (Roche) with $2 \mu \mathrm{l}$ of cDNA and $10 \mathrm{pmol}$ of each primer as described. ${ }^{44}$ Relative gene expression was expressed as a ratio of the expression level of the gene of interest to that of Hypoxanthine-phosphoribosyl-transferase (HPRT) RNA determined in the same sample. Reaction conditions were $4 \mathrm{mM} \mathrm{MgCl}_{2}\left(95^{\circ} \mathrm{C}\right.$ for $10 \mathrm{~s}, 61^{\circ} \mathrm{C}$ for $15 \mathrm{~s}, 72^{\circ} \mathrm{C}$ for $30 \mathrm{~s}$ ) for UPAR (P1: GCTGTACCCACTCAGAGAAGAC; P2: GTCACCACATCCAGGCACTGTT), $2 \mathrm{mM} \mathrm{MgCl} 2\left(95^{\circ} \mathrm{C}\right.$ for $10 \mathrm{~s}, 55^{\circ} \mathrm{C}$ for $15 \mathrm{~s}$, $72^{\circ} \mathrm{C}$ for $15 \mathrm{~s}$ ) for IFN $\alpha$ (P1: GTGAGGAAATACTTCCAAAGAATCAC; P2: 
TCTCATGATTTCTGCTCTGACAA) and $2 \mathrm{mM} \mathrm{MgCl} 2,\left(95^{\circ} \mathrm{C}\right.$ for $10 \mathrm{~s}, 50^{\circ} \mathrm{C}$ for $15 \mathrm{~s}, 72^{\circ} \mathrm{C}$ for $25 \mathrm{~s}$ ) for HPRT (P1: GACTTTGCTTTCCTTGGTCA; P2: GGCTTTGTATTTTGCTTTTCC). Specific amplification was controlled by melting curve analysis and by gel electrophoresis. ${ }^{45}$

Immunoblot analysis. Adherent and supernatant cells were lyzed in a buffer containing $50 \mathrm{mM}$ Tris; pH 7.4, $0.25 \mathrm{M} \mathrm{NaCl}, 1 \mathrm{mM}$ EDTA, $0.1 \%$ Triton X-100, $0.1 \mathrm{mM}$ EGTA, $5 \mathrm{mM} \mathrm{Na}_{3} \mathrm{VO}_{4}, 50 \mathrm{mM} \mathrm{NaF}$ and protease inhibitors (Complete, Mini, EDTA-free, Roche). Gel electrophoresis and blotting were carried out with 5-10 $\mu \mathrm{g}$ denatured protein lysate utilizing the Xcell SureLock Mini-Cell apparatus with $4-12 \%$ Gels in MES SDS buffer and PVDF membranes, according to the manufacturer's protocol (Invitrogen). After blocking (Western blocking reagent in PBS, Roche), blots were incubated with primary antibodies for $1 \mathrm{~h}$ at room temperature or overnight at $4{ }^{\circ} \mathrm{C}$. Following washes with $0.1 \%$ Tween-20 (Sigma) in PBS and $1 \mathrm{~h}$ of incubation with HRP-conjugated secondary antibodies, blots were washed and visualized (ECL plus Western Blotting Detection System, Amersham Pharmacia Biotech, Freiburg, Germany). Protein levels of $\beta$-actin were analyzed as a control for constant loading and transfer.

Quantification of viable cells. Viable cells were quantified in six-well dishes utilizing a fluorimetric assay (CellTiter-Blue Cell Viability Assay, Promega, Mannheim, Germany). Viable cells with intact metabolism are determined by their ability to reduce cell-permeable resazurin to fluorescent resorufin. Medium was replaced with $750 \mu \mathrm{l}$ of culture medium and $150 \mu \mathrm{l}$ of CellTiter-Blue reagent. After $1 \mathrm{~h}$ incubation at $37^{\circ} \mathrm{C}$ fluorescence was measured.

Quantification of apoptotic and dead Cells. Adherent and supernatant cells were analyzed by staining with FITC-labelled Annexin-V (Roche) and propidium iodide (Sigma). Annexin-V staining was performed according to the manufacturer's instructions. Propidium iodide was added to a final concentration of $0.5 \mu \mathrm{g} / \mathrm{ml}$ and cells were analyzed by flow cytometry and CellQuest software (Becton Dickinson, Heidelberg, Germany).

Skin reconstruction. Skin reconstructs were prepared as described with modifications. ${ }^{43}$ Three days before seeding, $1205 \mathrm{Lu}$ melanoma cells were transfected with siRNAs. $6 \times 10^{5}$ keratinocytes were mixed with transfected melanoma cells at a ratio of $8: 1$ and seeded on each contracted collagen gel. Experiments were terminated 15 days after seeding. Tumor growth in the reconstructs was evaluated by microscopic determination of the size and invasion of each tumor nest. Tumor invasion was defined by the maximum invasion of the tumor cells into the dermis, that is, collagen matrix.

Statistical analysis. For statistical analysis Student's $t$-test was used to assess the significance of mean differences between UPAR and control siRNAtreated cells. Differences were considered significant at a $P$-value of 0.05 , twotailed.

Acknowledgements. We thank Viktor Magdolen for reagents, Ursula Nägele for technical assistance and Phillip Bruhns for support in the statistical analysis. This work was supported by Deutsche Krebshilfe, Dr. Mildred Scheel Stiftung (Grant 102173-De 1) and by the DFG (Graduiertenkolleg 1202).

1. Hanahan D, Weinberg RA. The hallmarks of cancer. Cell 2000; 100: 57-70.

2. Sidenius N, Blasi F. The urokinase plasminogen activator system in cancer: recent advances and implication for prognosis and therapy. Cancer Metastasis Rev 2003; 22: 205-222.

3. Krol J, Kopitz C, Kirschenhofer A, Schmitt M, Magdolen U, Kruger A et al. Inhibition of intraperitoneal tumor growth of human ovarian cancer cells by bi- and trifunctional inhibitors of tumor-associated proteolytic systems. Biol Chem 2003; 384: 1097-1102.

4. Rofstad EK, Rasmussen H, Galappathi K, Mathiesen B, Nilsen K, Graff BA. Hypoxia promotes lymph node metastasis in human melanoma xenografts by up-regulating the urokinase-type plasminogen activator receptor. Cancer Res 2002; 62: 1847-1853.

5. Mohan PM, Chintala SK, Mohanam S, Gladson CL, Kim ES, Gokaslan ZL et al. Adenovirus-mediated delivery of antisense gene to urokinase-type plasminogen activato receptor suppresses glioma invasion and tumor growth. Cancer Res 1999; 59: 3369-3373.

6. Quattrone A, Fibbi G, Anichini E, Pucci M, Zamperini A, Capaccioli S et al. Reversion of the invasive phenotype of transformed human fibroblasts by anti-messenger oligonucleotide inhibition of urokinase receptor gene expression. Cancer Res 1995; 55: 90-95.
7. Liu D, Aguirre Ghiso J, Estrada Y, Ossowski L. EGFR is a transducer of the urokinase receptor initiated signal that is required for in vivo growth of a human carcinoma. Cancer Cell 2002; 1: 445-457.

8. May AE, Kanse SM, Lund LR, Gisler RH, Imhof BA, Preissner KT. Urokinase receptor (CD87) regulates leukocyte recruitment via beta 2 integrins in vivo. J Exp Med 1998; 188 1029-1037.

9. Wei Y, Lukashev M, Simon DI, Bodary SC, Rosenberg S, Doyle MV et al. Regulation of integrin function by the urokinase receptor. Science 1996; 273: 1551-1555.

10. Chapman HA, Wei Y. Protease crosstalk with integrins: the urokinase receptor paradigm. Thromb Haemost 2001; 86: 124-129.

11. Wei $Y$, Yang X, Liu Q, Wilkins JA, Chapman HA. A role for caveolin and the urokinase receptor in integrin-mediated adhesion and signaling. J Cell Biol 1999; 144: $1285-1294$

12. Aguirre Ghiso JA. Inhibition of FAK signaling activated by urokinase receptor induces dormancy in human carcinoma cells in vivo. Oncogene 2002; 21: 2513-2524.

13. de Vries TJ, Quax PH, Denijn M, Verrijp KN, Verheijen JH, Verspaget HW et al. Plasminogen activators, their inhibitors, and urokinase receptor emerge in late stages of melanocytic tumor progression. Am J Pathol 1994; 144: 70-81.

14. Quax PH, van Muijen GN, Weening-Verhoeff EJ, Lund LR, Dano K, Ruiter DJ et al. Metastatic behavior of human melanoma cell lines in nude mice correlates with urokinasetype plasminogen activator, its type- 1 inhibitor, and urokinase-mediated matrix degradation. J Cell Biol 1991; 115: 191-199.

15. The editors of Nat Cell Biol Wither RNAi? Nat Cell Biol 2003; 5 : 489-490.

16. Hornung V, Guenthner-Biller M, Bourquin C, Ablasser A, Schlee M, Uematsu S et al. Sequence-specific potent induction of IFN-alpha by short interfering RNA in plasmacytoid dendritic cells through TLR7. Nat Med 2005; 11: 263-270.

17. Green DR. Apoptotic pathways: paper wraps stone blunts scissors. Cell 2000; 102 $1-4$

18. Oltvai ZN, Milliman CL, Korsmeyer SJ. Bcl-2 heterodimerizes in vivo with a conserved homolog, Bax, that accelerates programmed cell death. Cell 1993; 74: 609-619.

19. Eisenmann KM, VanBrocklin MW, Staffend NA, Kitchen SM, Koo HM. Mitogenactivated protein kinase pathway-dependent tumor-specific survival signaling in amelanoma cells through inactivation of the proapoptotic protein bad. Cancer Res 2003; 63: 8330-8337.

20. Hess AR, Postovit LM, Margaryan NV, Seftor EA, Schneider GB, Seftor RE et al. Focal adhesion kinase promotes the aggressive melanoma phenotype. Cancer Res 2005; 65 : 9851-9860.

21. Golubovskaya VM, Gross S, Kaur AS, Wilson RI, Xu LH, Yang XH et al. Simultaneous inhibition of focal adhesion kinase and SRC enhances detachment and apoptosis in colon cancer cell lines. Mol Cancer Res 2003; 1: 755-764.

22. Golubovskaya VM, Finch R, Cance WG. Direct interaction of the N-terminal domain of focal adhesion kinase with the N-terminal transactivation domain of p53. J Biol Chem 2005; 280 25008-25021.

23. Golubovskaya V, Kaur A, Cance W. Cloning and characterization of the promoter region of human focal adhesion kinase gene: nuclear factor kappa B and $p 53$ binding sites. Biochim Biophys Acta 2004; 1678: 111-125.

24. Berking $\mathrm{C}$, Herlyn M. Human skin reconstruct models: a new application for studies of melanocyte and melanoma biology. Histol Histopathol 2001; 16: 669-674.

25. Blasi F, Carmeliet P. uPAR: a versatile signalling orchestrator. Nat Rev Mol Cell Biol 2002; 3: $932-943$.

26. Yanamandra N, Konduri SD, Mohanam S, Dinh DH, Olivero WC, Gujrati M et al. Downregulation of urokinase-type plasminogen activator receptor (UPAR) induces caspase-mediated cell death in human glioblastoma cells. Clin Exp Metastasis 2000; 18: $611-615$.

27. Pulukuri SM, Gondi CS, Lakka SS, Jutla A, Estes N, Gujrati M et al. RNA interferencedirected knockdown of urokinase plasminogen activator and urokinase plasminogen activator receptor inhibits prostate cancer cell invasion, survival, and tumorigenicity in vivo. J Biol Chem 2005; 280: 36529-36540.

28. Vousden KH, Lu X. Live or let die: the cell's response to p53. Nat Rev Cancer 2002; 2 594-604.

29. Satyamoorthy K, Chehab NH, Waterman MJ, Lien MC, El-Deiry WS, Herlyn M et al Aberrant regulation and function of wild-type p53 in radioresistant melanoma cells. Cell Growth Differ 2000; 11: 467-474.

30. Bardeesy N, Bastian BC, Hezel A, Pinkel D, DePinho RA, Chin L. Dual inactivation of RB and p53 pathways in RAS-induced melanomas. Mol Cell Biol 2001; 21: 2144-2153.

31. Bao W, Stromblad S. Integrin \{alpha\}v-mediated inactivation of $p 53$ controls a MEK1 dependent melanoma cell survival pathway in three-dimensional collagen. J Cell Biol 2004 167: 745-756.

32. Schuler M, Bossy-Wetzel E, Goldstein JC, Fitzgerald P, Green DR. p53 induces apoptosis by caspase activation through mitochondrial cytochrome c release. J Biol Chem 2000; 275 7337-7342.

33. Schmitt CA, Fridman JS, Yang M, Lee S, Baranov E, Hoffman RM et al. A senescence program controlled by p53 and p16INK4a contributes to the outcome of cancer therapy. Cell 2002; 109: 335-346.

34. Bowen AR, Hanks AN, Allen SM, Alexander A, Diedrich MJ, Grossman D. Apoptosis regulators and responses in human melanocytic and keratinocytic cells. J Invest Dermatol 2003; 120: 48-55. 
35. Carriero MV, Del Vecchio S, Capozzoli M, Franco P, Fontana L, Zannetti A et al. Urokinase receptor interacts with alpha(v)beta5 vitronectin receptor, promoting urokinase-dependen cell migration in breast cancer. Cancer Res 1999; 59: 5307-5314.

36. Satyamoorthy K, Li G, Gerrero MR, Brose MS, Volpe P, Weber BL et al. Constitutive mitogen-activated protein kinase activation in melanoma is mediated by both BRAF mutations and autocrine growth factor stimulation. Cancer Res 2003; 63: 756-759.

37. Davies H, Bignell GR, Cox C, Stephens P, Edkins S, Clegg S et al. Mutations of the BRAF gene in human cancer. Nature 2002; 417: 949-954.

38. Ilic D, Almeida EA, Schlaepfer DD, Dazin P, Aizawa S, Damsky CH. Extracellular matrix survival signals transduced by focal adhesion kinase suppress p53-mediated apoptosis. J Cell Biol 1998; 143: 547-560.

39. Golubovskaya V, Beviglia L, Xu LH, Earp III HS, Craven R, Cance W. Dual inhibition of focal adhesion kinase and epidermal growth factor receptor pathways cooperatively induces death receptor-mediated apoptosis in human breast cancer cells. J Biol Chem 2002; 277: 38978-38987.

40. Reynolds A, Leake D, Boese Q, Scaringe S, Marshall WS, Khvorova A. Rational siRNA design for RNA interference. Nat Biotechnol 2004; 22: 326-330.
41. Ui-Tei K, Naito $Y$, Takahashi F, Haraguchi T, Ohki-Hamazaki $H$, Juni A et al. Guidelines for the selection of highly effective siRNA sequences for mammalian and chick RNA interference. Nucleic Acids Res 2004; 32: 936-948.

42. Marschall C, Lengyel E, Nobutoh T, Braungart E, Douwes K, Simon A et al. UVB increases urokinase-type plasminogen activator receptor (UPAR) expression. J Invest Dermatol 1999; 113: 69-76.

43. Berking C, Takemoto R, Schaider H, Showe L, Satyamoorthy K, Robbins $P$ et al. Transforming growth factor-beta1 increases survival of human melanoma through stroma remodeling. Cancer Res 2001; 61: 8306-8316.

44. Besch R, Giovannangeli C, Kammerbauer C, Degitz K. Specific inhibition of ICAM-1 expression mediated by gene targeting with Triplex-forming oligonucleotides. J Biol Chem 2002; 277: 32473-32479.

45. Besch R, Giovannangeli C, Schuh T, Kammerbauer C, Degitz K. Characterization and quantification of triple helix formation in chromosomal DNA. J Mol Biol 2004; 341: 979-989.

46. Luther T, Magdolen V, Albrecht S, Kasper M, Riemer C, Kessler H et al. Epitope-mapped monoclonal antibodies as tools for functional and morphological analyses of the human urokinase receptor in tumor tissue. Am J Pathol 1997; 150: 1231-1244. 